\title{
52
}

\section{A Lifelong Learning Course Based on Learning Objectives}

\author{
Robert Aiken and Cheryl Sandås \\ Temple University, Computer and Information Sciences Department, 038-24, Philadelphia, PA \\ 19122, USA \\ aiken@joda.cis.temple.edu
}

Keywords: lifelong leaming/education, pedagogy, collaborative learning, fluency in information technology

\begin{abstract}
This paper describes our approach for developing a second level course that provides a strong foundation in information technology. The course was designed as a follow-up course to one often described as Computer Literacy. The course focuses on a hands-on-use of the technology in different complex, research and information-rich environments for students who are not computer and information science majors. In this paper we discuss how the course was developed after the authors carefully delineated the pedagogical goals they wanted to achieve. Both the advantages and disadvantages of organising a course in this manner are discussed.
\end{abstract}

\section{INTRODUCTION}

Information Technology (IT) is central to modern society (Toffler and Toffler 1995). Learning to use IT effectively in individual and organisational domain-specific processes cannot be done in a single step. Such learning requires appropriate introductory concepts, experiences, and motivations, and a life-long commitment to learning.

Courses that introduce IT generally fall into one of the following categories: 'computer literacy', 'programming', 'great ideas of computer science', and 'computer and society'. Such courses seldom combine the following elements: understanding of IT ideas and instruments, 
understanding of IT's role in framing and solving specific problems in various disciplines, and the ability to actually use IT to solve these problems. Students who are interested in specific themes and subject domains, such as chemistry, sociology, or anthropology need to understand IT from the perspective of these domains.

The question we address is how to bring students to the level beyond the introductory course. At this new level students should be able to integrate IT into the problem-solving logic and operation of their specific disciplines. We propose a new course to achieve this transformation. It will demonstrate through complex case studies the power of IT integration. We propose indepth case studies as the best approximation to apprenticeship learning. Additional details on the case study approach and framework can be found in Aiken et al. (2000).

We should note here that the planning for this project has been underway for several years and was independent of the 'Being Fluent with Information Technology' report that was written by a Committee on Information Technology Literacy and published by the National Academy Press (1999). However, in many ways our ideas and concerns are similar. What we discuss is one specific way to address the concerns addressed in this report of how to make a larger number of college/university students fluent in technology and life long users of IT.

Principal objectives of our proposal also include establishing a framework to develop portable case studies, assessing the effectiveness of the course in achieving its stated goals, and disseminating our results as widely as possible. This is certainly consistent with the above mentioned report which states, "In summary, FIT individuals, those who know a starter set of IT skills, who understand the basic concepts on which IT is founded, and who have engaged in the higher-level thinking embodied in the intellectual capabilities, should use information technology confidently, should come to work ready to learn new business systems quickly and use them effectively, should be able to apply IT to personally relevant problems, and should be able to adapt to the inevitable change as IT evolves over their lifetime."

\section{PEDAGOGICAL OBJECTIVES}

In designing this course we decided to proceed from a set of pedagogical objectives that are consistent with standards in general use (International Society for Technology in Education 1998).

The following six objectives were the ones chosen to provide the backbone for the course: 


\section{Basic operations and concept}

- Students demonstrate a sound understanding of the nature and operation of technology systems.

- Students are proficient in the use of technology.

Social, ethical, and human issues

- Students understand the ethical, cultural, and societal issues related to technology.

- Students practice responsible use of technology systems, information, and software.

Technology productivity tools

- Students use technology tools to enhance learning, increase productivity, and promote creativity.

- Students use productivity tools to collaborate in constructing technology-enhanced models, preparing publications, and producing other creative works.

Expressive and collaborative communication

- Students use IT to collaborate, and interact with peers and other audiences.

- Students use a variety of media and formats to communicate information and ideas effectively to multiple audiences.

Technology research tools

- Students use technology to locate, evaluate, and collect information from a variety of sources.

- Students use technology tools to process data and report results.

- Students evaluate and select new information resources and technological innovations based on the appropriateness to specific tasks.

Technology problem-solving and decision-making tools

- Students use technology resources for solving problems and making informed decisions.

- Students employ technology in the development of strategies for solving problems in the real world.

These were the primary objectives that we wanted to emphasise in the course. In order to better understand how these objectives helped influence the design of the course we will discuss topics that were covered under one of these objectives and describe how they assisted us in developing the course and presenting the material.

\subsection{Social, ethical and human issues}

The first author developed most of the material for this objective. Our overarching goal with this objective was that students understand the ethical, 
cultural, and societal issues related to technology. The crucial point is that technology, though by itself neutral, can have wide reaching and potentially harmful effects. So the question becomes not so much, "Can we do it?", but "Should we do it?". This topic was presented in week 11 of the course after a number of technical subjects had previously been covered. Students were asked to read a paper, which discusses the role of ethics in the development of Artificial Intelligence systems of the future; with particular emphasis on educational applications (Aiken and Epstein 2000).

This paper built on previous class discussions, which focused on articles that students had collected in a previous assignment regarding controversial uses of computers in society. The next lecture was devoted to exploring in some detail three (out of more than 40) scenarios on the web that paint a rather grim picture of what the future might become if we allow computers to become too intelligent and subsequently rely on them too much. (see www.cs.wcupa.edu/ epstein/AIStories.html.) In order to anchor this material we found it useful to use articles and stories to facilitate class discussion about ramifications of the material presented. Also students were required to write a three-page paper analysing one of the three scenarios.

\subsection{Expressive and collaborative communication}

In addition to promoting class discussion by designing participatory exercises and open-ended discussion questions, we required the students to either choose a project from the ones we offer or design and develop their own web-based project. Our goal was to have them use tools similar to those they had explored during the semester and to acquire greater facility with all the methodologies we had presented for building web-based material. The web is a media for disseminating information to and interacting with a wide spread population at minimal cost. Thus, we felt that it was essential that students master the skill of rendering information in an organised and appealing way on the web. Each group of two students was required to present their results to the class on the last day of class in addition to turning in a written report. One of our objectives was to work with them on collaboration strategies as well as provide them an opportunity (challenge) to demonstrate their project and give an oral presentation.

\subsection{Pedagogical objectives in the lab}

The lab portion of the class provides an environment for the concepts presented in lecture to be implemented and to address many of the pedagogical objectives. We accomplish this through various hands-on exercises and projects that support the material covered in the lectures. 
Among the pedagogical objectives covered in the lab are basic operations and concepts, technology productivity tools, expressive and collaborative communication, technology problem-solving and decision-making tools. A few of these objectives will be discussed in detail and compared to the approach of Snyder and his colleagues at the University of Washington who take a project and programming based approach in their Fluency with IT course (www.cs.washington.edu/education/courses/100/99au).

Our main objective in the lab is to focus on the concepts presented in lectures using IT. We do not focus on basic computer skills because all of the students have taken a 'Computer Literacy' course where these skills are provided. However, basic operations and concepts of IT are covered as we utilise a variety of software applications such as Excel, Idrisi (a geographic information system), Alchemy (molecular modelling software), FrontPage, Word, Netscape/Explorer, Intelligent Tutoring Systems, and multimedia software. During the course students must demonstrate their knowledge of IT by creating and maintaining web pages, by completing analytical exercises and by presenting results using different software such as Idrisi, Alchemy, and Microsoft Excel.

Since a wide variety of software is used ranging from the basic to the very complex, we are presented with certain opportunities and challenges. The opportunities are that by teaching the students how to use new software we can provide in-depth comparisons between many different software applications as well as review some of the basic computer skills that the students acquired in the 'Computer Literacy' course. In this way, we can cover the concepts of files, help, features and error recovery in addition to mentioning these concepts while students use the software applications and navigate the web. The main challenge is to teach the students enough of the software that they can perform some of the analyses that are presented in lecture and lab plus learn enough of the key concepts to interpret the results.

In order to meet this challenge, three case study lecturers (colleagues from Anthropology, Chemistry and Sociology) first take the students through a sample exercise in the lab so the students can ask questions and get a sense of the process the researcher follows to analyse their models. In the labs associated with all the lectures, multimedia tutorials that we have created, class presentations, and written instructions are used to teach new software. On-line help is also available.

Snyder and his colleagues use Notepad, Word, and Netscape to create and view web pages, Access, and Visual Basic. By focusing on fewer software applications, they are able to cover each in more depth thus allowing them to develop more complex projects. Using Visual Basic gives the instructors the flexibility to address a wide array of topics ranging from computer modelling to algorithmic thinking. However, it does require 
students to learn a programming language - something that we wanted to avoid in our course. We did not want the students to spend time acquiring basic programming skills at the expense of utilising a wide range and variety of application software.

The pedagogical objective of appropriately using IT to solve problems is primarily met through the lab exercises associated with the case studies. In lecture, the case study lecturers discuss their motivation, model and methodology for examining the problems that they present, and in the lab, they lead the students through a series of exercises to solve these problems. The students are then given an assignment that necessitates using this software to solve a problem related to the one that was presented. The exercises provide the students with examples of how IT is used in different disciplines to solve complex problems and the challenges involved in using IT in this manner. The challenges include selecting the appropriate IT for solving the problem and verifying the accuracy of the results.

In most cases, the case study lecturers have chosen the IT they use from several alternatives. Some of the IT are domain specific while others are not. In the case where the IT selected is not domain specific we discuss why the lecturer thought it would work in their domain. The process of making this decision is also discussed briefly with the students. Since most complex problems are solved in multiple stages, potentially using different software at each stage, the lecturers discuss the problem solving process with students from beginning to end. Through these discussions in the lab and the lecture, students obtain a better understanding of the procedures researchers follow to solve problems. In this way we believe that students will have 'role models' - people from various disciplines who demonstrate how technology has, and continues to, effect how they think and work.

The FIT course at the University of Washington also addresses this objective with their modelling project. In one modelling assignment they use Visual Basic to simulate the falling of raindrops on pavement. The students are asked to embellish and experiment with it in order to see how computers are used to model the world, experiment with a model to observe how its different characteristics affect the result, and understand how the simplifying assumptions of the model affect the answers. We address the same issues that they do, however, we also address IT choice and research motivation, which is a component that a case study approach can add.

\section{CONCLUSIONS}

Students enjoy using a variety of tools to solve different problems but there is a question of how to maintain coherence in the course across topics. 
Our solution in part has been to try and develop some common themes or threads throughout the course such as examining different problems using a similar systems design approach.

Lecturers were given the flexibility and responsibility for designing the lab assignments that accompanied their lectures. This helped integrate the lectures and labs for the individual instructors But their lecture styles differed considerably so the composition and form of the labs varied as well. Our solution was to have the graduate assistant assume responsibility for running all the labs with the goal of making the work across the labs more consistent.

Having lecturers from different disciplines provides a successful, interdisciplinary flavor to the course but trying to determine how to provide 'credit' to each person is very difficult. Our solution was made easier by the fact that a grant to fund the development of the course permitted us to pay the lecturers for some of their time.

This course provides schools a solution as to how to go beyond a typical Computer Literacy course for non-computer science majors but that raises the question of how to staff the course. This is especially critical since most computer and information science departments do not have sufficient resources to even teach all the courses for their own students. Our solution was to not include programming and design the course so someone who was not a computer scientist, but who was knowledgeable about computing could teach it.

In general we feel that the course has met our most important objective that of providing the students with sophisticated computing skills and the knowledge that it will be necessary for them to continually hone these skills. As each generation becomes more computing proficient the need for such a course will be obviated. But in the meantime this course provides a foundation to not only make students computer fluent, but to impress upon them the importance of staying abreast of technological developments.

\section{ACKNOWLEDGEMENTS}

The development of this course is in part funded by a grant from the National Science Foundation, DUE 9951418. The authors would like to thank Professors N. Kock and M. Mandviwalla for their participation in the development and teaching of the course and to Professors D. Dalton, D. Elesh and A. Ranere for both their design of the case studies, and their teaching of them. 


\section{REFERENCES}

Aiken, R., Mandviwalla, M., Kock N. and Sandås C. (2000) Life Long Learning: Reaching out to Non-CIS Majors. In Proceedings of IFIP $16^{\text {th }}$ World Computer Congress 2000, Publishing House of Electronics Industry, Beijing, August 2000, pp. 100-106.

Aiken, R. and Epstein R. G. (2000) Ethical Guidelines for AI in Education: Starting a Conversation. Journal of Artificial Intelligence in Education, 11, No. 2, pp. 163-176. Committee on Information Technology Literacy (1999) Being Fluent with Information Technology. National Academy Press, Washington, D.C.

International Society for Technology in Education (ISTE) - National Educational Technology Standards (NETS) Project (1998) Technology Foundation Standards for All Students. [http://cnets.iste.org/sfors.htm] 5.5.2001.

Toffler, A. and Toffler, H. (1995) Creating a New Civilization: The Politics of the Third Wave. Turner Publications, New York.

\section{BIOGRAPHY}

Robert Aiken is a Professor in the Computer and Information Sciences Department. His primary research areas are applying Artificial Intelligence tools and techniques to Collaborative Learning Environments, and issues related to making effective use of technology in teaching and learning.

Cheryl Sandås is a graduate student at Temple University. She is interested in the impact of technology on education. 